\title{
A enfermagem e o aleitamento materno de recém-nascidos portadores de fissura labial e/ou palatina.
}

Nursing and breastfeeding of newborns with cleft lip and / or palate.

Enfermería y lactancia de recién nacidos con labio leporino y / o paladar hendido.

Ellis do Valle Souza Gregory ${ }^{1}$, Alessandra da Silva Souza ${ }^{2^{*}}$

Como citar esse artigo. Gregory, EVS; Souza, AS. A enfermagem e o aleitamento materno de recém-nascidos portadores de fissura labial e/ou palatina. Revista Pró-UniverSUS. 2020 Jan./Jun.; 11 (1): 02-05

\begin{abstract}
Resumo
O aleitamento materno é a mais sábia estratégia natural de vínculo, afeto, proteção e nutrição para a criança, porém esse processo de amamentação torna-se comprometido em crianças com fenda labial e/ou palatina (FLP) devido às alterações nas estruturas anatômicas da face, que interferem na sucção e deglutição. O presente estudo tem como objetivo analisar os cuidados de enfermagem referente a amamentação nestas situações especiais e descrever quais são as ações desenvolvidas pela equipe de enfermagem neste processo. Foi realizada uma pesquisa de campo, descritiva com abordagem qualitative, sendo entrevistadas 13 profissionais da equipe de enfermagem. Os resultados mostram que a equipe de enfermagem reconhece a importância do aleitamento materno, incentiva a ordenha manual, porém a administração do leite é fornecido pelo recurso da sonda orogástrica, o que nos mostra que este manejo é definido através de uma avaliação individualizada ao recém-nascido pela equipe multiprofissional.
\end{abstract}

Palavras-chave: Aleitamento materno, enfermagem, fissura labial e palatina.

\begin{abstract}
Breastfeeding is the wisest natural bonding, affection, protection and nutrition strategy for the child, but this breastfeeding process becomes compromised in children with cleft lip and / or palate due to changes in the anatomical structures of the face., which interfere with suction and swallowing. The present study aims to analyze nursing care regarding breastfeeding in these special situations and describe what are the actions developed by the nursing team in this process. A descriptive field research with a qualitative approach was conducted, and 13 nursing team professionals were interviewed. The results show that the nursing team recognizes the importance of breastfeeding, encourages manual milking, but the administration of milk is provided by the orogastric tube, which shows that this management is defined through an individualized evaluation of the newborn. born by the multiprofessional team.
\end{abstract}

Keywords: Breastfeeding, nursing, cleft lip and palate.

\section{Resumen}

La lactancia materna es la estrategia natural más sabia de vinculación, afecto, protección y nutrición para los niños, pero este proceso de lactancia se ve comprometido en los niños con labio leporino y / o paladar hendido (CLP) debido a cambios en las estructuras anatómicas de la cara., que interfieren con la succión y la deglución. El presente estudio tiene como objetivo analizar la atención de enfermería con respecto a la lactancia materna en estas situaciones especiales y describir cuáles son las acciones desarrolladas por el equipo de enfermería en este proceso. Se realizó una investigación de campo descriptiva con un enfoque cualitativo y se entrevistó a 13 profesionales del equipo de enfermería. Los resultados muestran que el equipo de enfermería reconoce la importancia de la lactancia materna, alienta el ordeño manual, pero la administración de leche es proporcionada por el tubo orogástrico, lo que demuestra que este manejo se define a través de una evaluación individualizada del recién nacido. nacido por el equipo multiprofesional.

Palabras clave: Lactancia materna, enfermería, labio leporino y paladar hendido.

Afiliação dos autores: 1. Acadêmico do Curso de Enfermagem, Universidade de Vassouras. RJ, Brasil. Email: ellis greegory@hotmail.com ORCID: https://orcid.org/0000-00020595-2188

2. Mestre. Professor do Curso de Enfermagem, Universidade de Vassouras. RJ, Brasil. Email: alesouza22@yahoo.com.br ORCID: https://orcid.org/0000-0002-9009-9774

* Email de correspondencia: alesouza22@yahoo.com.br 


\section{Introdução}

A amamentação, é definida como um processo no qual o aleitamento ocorre através da sucção direta da mama da mãe, é a maneira mais sábia de atender aos aspectos nutricionais, imunológicos oportunizados pelo leite materno, pois contém micronutrientes responsáveis pelo crescimento e desenvolvimento da criança, assim como bioativos como oligossacarídeos, proteínas e peptídeos que atuam diretamente na proteção da criança contra infecções. ${ }^{1}$

Amamentar é muito mais do que nutrir a criança. É um processo que envolve interação profunda entre mãe e filho, atuando no estado nutricional da criança, em sua capacidade de se defender de infecções, em sua fisiologia e no seu desenvolvimento cognitivo e emocional, e em sua saúde no longo prazo, além de ter implicações na saúde física e psíquica da mãe. ${ }^{2}$

Porém, esse processo de amamentação torna-se comprometido em recém-nascidos com fenda labial e/ ou palatina (FLP) em decorrência das alterações nas estruturas anatômicas da face, que interferem na sucção e deglutição. ${ }^{1}$

Devido a FLP causar limitações e complicações, o paciente se torna exposto a um grande risco de desnutrir, principalmente pela sucção insuficiente, a deglutição excessiva de ar com reflexos nasais e engasgos, ao cansaço e ao gasto energético decorrente da alimentação demorada, tendo uma baixa ingestão de nutrientes. Sendo o principal fator para o atraso cirúrgico, o baixo ganho ponderal. Exaltando assim, a importância da atenção ao estado nutricional da criança com fissura labiopalatina, com orientação precoce aos responsáveis da criança quanto a sua alimentação. ${ }^{3}$

Portanto, decorrente da grande importância do aleitamento materno, o mesmo deve ser encorajado até o sexto mês de vida, sempre que possível, por seus inúmeros benefícios nutricionais.

\section{Metodologia}

Trata-se de uma pesquisa de campo, descritiva com abordagem qualitativa, aprovada pelo Comitê de ética em Pesquisa (CEP) da Universidade de Vassouras (UV) sob o número 3.479.289. A pesquisa foi realizada com a equipe de enfermagem do Setor de Unidade de Terapia Intensiva Neonatal - Centro Integrado de Saúde Unidade Materno Infantil, localizado na cidade de Vassouras- RJ.

Participaram da pesquisa a equipe técnica de enfermagem e enfermeiros que atuam na Unidade de Terapia Intensiva Neonatal, que aceitaram participar da pesquisa, assinando o termo de Consentimento Livre Esclarecido (TCLE) ANEXO A conforme a resolução n²466, de Dezembro de 2012 do Conselho Nacional de
Saúde. Os dados foram coletados de agosto a setembro de 2019.

Como critério de elegibilidade foram incluídos todos os profissionais integrantes da equipe de enfermagem do setor de UTI Neonatal do CIS - Unidade Materno-Infantil e foram excluídos profissionais de outros setores. Os dados foram coletados mediante entrevista semiestruturada. Os participantes da pesquisa tiveram sua identidade preservada, a pesquisadora utilizou de pseudônimo com nome de pedras preciosas exemplo: pérola, rubi e etc.

A pesquisa foi submetida ao Comitê de Ética e Pesquisa da instituição em que foi realizada conforme a resolução $n^{\circ} 466 / 2012$ do Conselho Nacional de Saúde - MS, que regulamenta as normas de Pesquisa envolvendo Seres Humanos.

Para realização da análise dos dados, primeiramente agrupamos informações colhidas em concordância com o objetivo da pesquisa e instrumento aplicado, foi realizada uma leitura exaustiva dos dados que proporcionaram a geração de categorias de análise e discussão dos dados obtidos com o estudo em tela.

\section{Resultados e Discussão}

Este estudo se insere na área de estudos da Saúde da Criança. Tentou-se encontrar respostas que conseguisse verificar como se dá a assistência da equipe de enfermagem no processo de aleitamento materno em recém-nascidos portadores de fissura labial e/ou palatina.

Inicialmente a análise dos dados está direcionada para a caracterização do perfil sócio demográfico da equipe de enfermagem, com um total de (13) treze entrevistados. Foram envolvidos dados temáticos, considerando as concepções mais frequentes: faixa etária, sexo, escolaridade, categoria profissional e tempo de trabalho.

Os dados coletados mostraram que a maioria da equipe de enfermagem entrevistada encontrava-se nas seguintes faixas etárias: 20 a 30 anos $(46,01 \%), 30$ à 40 anos $(30,76 \%)$ e 40 à 50 anos $(23,23 \%)$, onde $100 \%$ dos profissionais entrevistados eram do sexo feminino o que caracteriza ainda um grande predomínio de mulheres na profissão de enfermagem.

Sobre esta prevalência, a mulher é diferente do homem na maneira de trabalhar, por possuir características que podem contribuir no âmbito profissional, como ser sensível, delicada e caprichosa, mesmo assim ela ainda enfrenta desafios. ${ }^{4}$

A presença da mulher na profissão está associada à sua trajetória de ser um oficio eminentemente feminino, embora já se perceba um movimento à inserção do homem na profissão, embora não foi evidenciado neste estudo. ${ }^{5}$ 
Em relação a frequência de nascimento de recémnascidos portadores de fissura labial e/ou palatina, nas falas abaixo as participantes revelam a frequência de nascimento de recém-nascidos portadores de fissura labial e/ou palatina:

"Então, são poucos os casos que tiveram durante este tempo que estou na UTIneo, que eu me lembre, durante estes anos só tiveram uns 4 casos, no máximo 5, mas acredito que nem seja isso tudo" Pérola

"Não, até o momento só presenciei 2 casos, e dos 2 foram fissura labial junto com palatina" Opala

"Não, já $\quad$ presenciei $\quad$ somente 1

Através deste estudo, foi possivel observar que

Através deste estudo, foi possível observar que há baixa incidência de nascimento de recém-nascidos portadores de fissura labial e/ou palatina, sendo visto somente pelos profissionais que atuam há mais tempo nesta área e tiveram a oportunidade de presenciar alguns casos. Este achado se justifica pela localidade onde o trabalho foi realizado na cidade de Vassouras localizado no Centro-Sul do estado do Rio de Janeiro com entorno de $538,1 \mathrm{~km}^{2}$, E conta 34.439 habitantes.

A incidência das fissuras labiais/leporinas varia de acordo com a localização geográfica, raça e condição socioeconômica e tem uma distribuição média de aproximadamente 1 caso para cada 700 nativivos. $^{6}$

Ao serem questionadas como se dá o manejo do aleitamento materno com os bebês portadores de fissura labial e/ou palatina, os depoimentos abaixo revelam as condutas e recursos utilizados pelos profissionais frente ao manejo do aleitamento materno com bebes portadores de fissura labial e/ou palatina:

"Geralmente com a introdução de sonda e
dependendo do grau da fissura a gente tenta
o aleitamento pelo seio materno" Diamante

"No aleitamento materno a mãe vai fazer a ordenha $e$ a gente tem uma profissional, que é a fonoaudióloga, que irá fazer a avaliação e dependendo da fissura ela vai indicar juntamente com o médico que o bebê receba esse leite por sonda ou pelo seio materno" Jade

"Por sonda, chuquinha, copinho, até fazer a cirurgia reparadora, depende da avaliação da fono quanto a sucção do bebê" Aquamarine

É possível observar que as respostas foram sempre parecidas, com auxílio da sonda, porém, com a avaliação da fonoaudióloga, o que nos mostra que este manejo é definido através de uma avaliação individualizada ao paciente pela equipe multidisciplinar.

A dificuldade na amamentação ocorre devido a diminuição da eficiência na sucção e varia de acordo com a gravidade da lesão. Deste modo, a incapacidade para alimentar satisfatoriamente resulta de estresse materno e ansiedade e pode conduzir à falta de vínculo materno infantil. ${ }^{7}$

O posicionamento do mamilo é fundamental para o sucesso da amamentação e deve ser colocado na área mais íntegra do palato ou com o osso mais intacto, com o intuito de facilitar a compressão do mamilo e impedir que ele seja conduzido para o interior da fenda. No caso da fenda bilateral, a mãe deve projetar o mamilo para a parte inferior da cavidade oral e, se houver necessidade, pode também fazer a expressão da mama, como substituto do abocanhar da criança. ${ }^{1}$

A efetividade da amamentação deve ser realizada através da observação da mamada, da verificação do ganho de peso e da hidratação da criança com FLP. A falta de dados positivos durante o processo de amamentação pode ser um indicativo da necessidade da nutrição suplementar, com alimentação, mas não substitutive. ${ }^{1}$

Portanto, é possível observar através de estudos realizados que, o aleitamento materno no seio é possível, $\mathrm{e}$, analisando a minha pesquisa, observo que grande parte dos profissionais não possuem este conhecimento, pois os mesmos retratam a alimentação do recém-nascido portador de fissura labial e/ou palatina com o uso de sonda orogástrica.

\section{Conclusão}

O estudo buscou analisar a importância do aleitamento materno através de uma busca bibliográfica, associando ao recém nascido portador de fissura labial e/ou palatina. O aleitamento materno exclusivo até os 6 meses de vida, proporciona uma melhor qualidade de vida para o binômio. O leite materno é o ideal para o crescimento e desenvolvimento do bebê, protegendo-o contra infecções respiratórias, obesidade, entre outros, diminuindo a mortalidade infantil.

Em relação a esta situação especial, a amamentação pode se tornar comprometida, porém, após estudos, obeservo que o recém-nascido portador desta patologia possui os requisitos necessários para o aleitamento no seio materno, sendo necessário uma adequada assistência prestada ao paciente, tendo em vista o treinamento técnico, habilidade e sensibilidade da equipe multiprofissional.

Diante dos dados coletados, observo que o aleitamento materno no seio ainda não é a primeira opção da equipe, onde a maior parte dos entrevistados retratam a alimentação pela sonda, por isso, é necessário encorajar a enfermagem, como parte desta equipe, em sua função, que vai além da assistência durante o período de hospitalização, como também orientar e auxiliar a família deste recém-nascido quanto aos cuidados a serem realizados em casa, esclarecendo dúvidas neste processo da amamentação. 
Portanto, esta pesquisa de campo, junto da revisão bibliográfica realizada, foi de grande valia para o meu conhecimento como profissional de enfermagem. Percebemos as dificuldades que precisam ser enfrentadas por todos aqueles profissionais de saúde que estão envolvidos no tratamento para que se obtenha os melhores resultados.

\section{Referências}

1. Santos, Rosangela da Silva; Janini, Janaina Pinto; Oliveira, Helaine Maria da Silva. The transition of breastfeeding children with cleft palate and lip among women. Escola Anna Nery, 2019;23(1).

2. BRASIL. Ministério da Saúde, Secretaria da atenção de Saúde. Departamento de Atenção Básica. Saúde da Criança aleitamento materno e alimentação complementar. Brasília: Ministério da Saúde, 2015.

3. DA SILVA, Ysabele Caroline Oliveira; TEIXEIRA, Gabriela Luciana Santos Bastos; NEVES, Juliana Kelle Andrade Lemoine. Uma abordagem sobre a importância da atuação do profissional de nutrição no tratamento de crianças com fissuras labiopalatinas. Revista Eletrônica da Estácio Recife, 2018;4(1).

4. Brito JC, Neves MY, Oliveira SS, Rotenberg LS. Subjetividade e trabalho: o enfoque clínico e de gênero. Rev Bras Saúde Ocup. 2012.

5. Santos, A. A; Costa, O. R. S. Qualidade de vida no trabalho dos Profissionais de Enfermagem que atuam no período noturno em hospital Escola do Sul de Minas Gerais. Revista Ciências em Saúde, 2016;6(1).

6. Martelli Júnior, Hercílio; Orsi Júnior, Julian; Chaves, Marcelo Reis; et al. Estudo epidemiológico das fissuras labiais e palatais em Alfenas Minas Gerais - de 1986 a 1998. RPG: revista da pós-graduação, São Paulo, 2006;13(1):31-5.

7. Branco LL, Cardoso MC. Alimentação no recém-nascido em fissuras labiopalatinas. Universitas: Ciências da saúde.Brasília, 2013; 11(1): 57-70. 